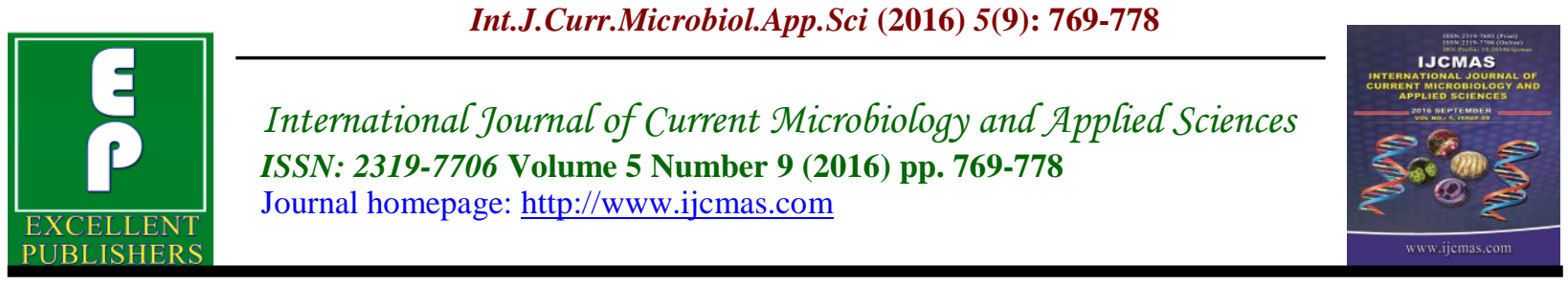

Original Research Article

http://dx.doi.org/10.20546/ijcmas.2016.509.088

\title{
Bioactivity of Fungal Endophytes associating with Allium Plants growing in Uzbekistan
}

\author{
L.I. Abdulmyanova ${ }^{1}$, F.K. Fayzieva ${ }^{2}$, D.M. Ruzieva ${ }^{1}$, G.A. Rasulova ${ }^{1}$, \\ R.S. Sattarova ${ }^{1 *}$ and T.G. Gulyamova ${ }^{1}$ \\ ${ }^{1}$ Department of Biochemistry and Biotechnology of Physiologically Active Compounds, \\ Institute of Microbiology of the Academy of Sciences RU, Uzbekistan \\ ${ }^{2}$ Department of Collection of Industrially Important Cultures of Microorganisms, \\ Institute of Microbiology of the Academy of Sciences RU, Uzbekistan \\ *Corresponding author
}

\begin{tabular}{|c|c|}
\hline & A B S T R A C T \\
\hline $\begin{array}{l}\text { Ke y w o r d s } \\
\text { Allium species, } \\
\text { endophytic fungi, } \\
\text { cytotoxicity, } \\
\text { antibacterial activ } \\
\text { antidiabetic activi }\end{array}$ & \multirow{3}{*}{$\begin{array}{l}\text { Sixteen endophytic fungi were isolated from endemic Allium species which } \\
\text { were collected from selected locations in Uzbekistan: south-western } \\
\text { KyzylKum, Kashkadarya region, Pap hills, foothills of Kuramin range, } \\
\text { foothills of the Nurata and Chatkal nature reserves. The isolates were tested } \\
\text { for antibacterial, antidiabetic and cytotoxic activity. Obtained data showed } \\
\text { that endophytes produce compounds with antibacterial, antidiabetic and } \\
\text { cytotoxic properties that indicate the potential of endophytic fungi } \\
\text { associated with Allium plants as a source of new secondary metabolites with } \\
\text { therapeutic value. }\end{array}$} \\
\hline Article Info & \\
\hline & \\
\hline
\end{tabular}

\section{Introduction}

Endophytes are the microorganisms that live in the intercellular space of a healthy plant tissues without causing symptoms of disease (Padhi et al., 2013; Strobel and Daisy, 2003). The symbiosis between plants and microorganisms is well known. In particular, the plant protects and feeds the endophyte which in response produce bioactive substances that enhance the growth and resistance of plants in environment (Nair and Padmavathy, 2014). Moreover, some endophytic microorganisms are characterized by their ability to synthesize the same metabolites as the host plant.
So, systematic investigation of endophytic fungi associated with different plants is necessary, and will not only provide with genetic information, but also may allow for new natural products with higher bioactivity to be found with potential application in medicine, agriculture and industry (Gutierrez et al., 2012; Pimentel et al., 2011).

The genus Allium which includes garlic (Allium sativum), leek (A. porrum), onion (A. серa), shnit-onions (A. schoenoprasum) consist of more than 700 other species that have been described in Afghanistan, 
Kazakhstan, Kyrgyzstan, Pakistan, Tajikistan, Turkmenistan, Uzbekistan, and Northern Iran (Augusti, 1996; Brewster, 2008; Maaß and Klaas, 1995). Ancient Chronicles reports about common onion (Allium cepa L.) and garlic (A. sativum L.) are coming out of this area to Europe during the times of antique civilization. Onion and garlic possess antidiabetic, antibiotic, hypocholesterolemic, fibrinolytic and other properties. Except for industrial crops, the local people use in diet a number of wild species but their therapeutic purposes are rarely reported (Jin-long et al., 2011; Keusgen et al., 2006; Navruzshoev, 1994). Research on endophytes from plants of the family Allium is a few. So, endophytic fungi isolated from garlic has a pronounced inhibitory effect on phytopathogens Rhizoctonia solani and Botrytis cinerea (Khassanov, 1996).

Several rare wild species of this plant inhabit in the territory of Uzbekistan (Keusgen et al., 2006; Rabinowitch and Currah, 2002). A systematic study of endophytic microorganisms as potential sources of new compounds relevant to the assessment of bioactivity of secondary metabolites, thus studies of endophytes of Allium plants are of great interest. In this context, the aim of this work was the isolation of endophytic fungi from two endemic Allium species and characterization of their antibacterial, cytotoxic and antidiabetic activity.

\section{Materials and Methods}

\section{Study Area and Material Sampling}

Plant material was collected from March to May 2012, 2013 and 2014 on the territory of the south-western KyzylKum (foothills of Mount Kulzhuntog), Kashkadarya region, Pap hills, foothills of Kuramin range (Uygurca), foothills of the Nurata and
Chatkal nature reserves and kindly provided by Dr. Tojibaev (Institute of Flora and Fauna Gene Pool of the Academy of Sciences RU). All plants were kept at a temperature of $+40 \mathrm{C}$. All plants were preserved at $+4^{\circ} \mathrm{C}$ temperature. Plant samples were identified and stored in a herbarium.

\section{Isolation of Endophytic Fungi}

Endophytic fungi were isolated by the method as described previously by Hazalin et al. (Hazalin et al., 2009). Roots, stems and leaves were respectively washed in tap water, sterilized in $70 \%$ ethanol for $1 \mathrm{~min}$ followed by $0.1 \% \mathrm{HgCl} 2$ for $7 \mathrm{~min}$, rinsed three times in de-ionized water, cut into segments approximately $5 \mathrm{~mm}$ in diameter and placed in $90 \mathrm{~mm}$ Petri dishes containing Czapek-Dox agarized medium with 50 $\mathrm{mg} / \mathrm{ml}$ chlortetracycline and $250 \mathrm{mg} / \mathrm{ml}$ streptomycin sulfate to inhibit bacterial growth. The plates were incubated for 7-14 days at $28{ }^{\circ} \mathrm{C}$. Different mycelia growing out of the segments were sub-cultured and individually maintained on antibiotics-free Czapek-Dox-agar medium. Colony morphology and growth and spore formation of the isolates were then studied on PotatoDextrose-agar medium.

\section{Endophytic Fungi Identification}

Isolated strains were identified by classical methods on the basis of morphology using pertinent monographs (Litvinov, 1967). Isolated strains were deposited at the Institute of Microbiology of the Uzbekistan Academy of Sciences where they were maintained at $+4{ }^{\circ} \mathrm{C}$.

\section{Fermentation}

To accumulate biomass for further extraction and determination of biological activity, endophytes were grown by 
submerged fermentation in $500 \mathrm{ml}$ flasks containing $100 \mathrm{ml}$ of Chapek-Dox liquid medium for 5 days at $28^{\circ} \mathrm{C}$.

\section{The Extraction of Secondary Metabolites of Endophytic Fungi}

To determine the antibacterial and antifungal activities, metabolites from biomass were extracted by methods as described previously by Lang et al. (Lang et al., 2005) with modifications described previously by Hazalin et al. (Hazalin et al., 2009). $5 \mathrm{~g}$ of biomass of each isolate was milled in a Potter homogenizer, transferred to a cone flask containing $50 \mathrm{ml}$ of ethyl acetate, and left for extraction at night on a shaker at room temperature. The mixture was filtered through filter paper (Whatman \#1) and $\mathrm{Na} 2 \mathrm{SO} 4(40 \mu \mathrm{g} / \mathrm{ml})$ was added. After the filtration, the extract was striped to dryness on a rotary evaporator and mixed with $1 \mathrm{ml}$ of dimethyl sulfoxide (DMSO). The resulting extract was used as a stock solution and stored at $+4{ }^{\circ} \mathrm{C}$.

\section{Antimicrobial Assay}

The fungal extracts were screened using the agar diffusion method for antimicrobial activity against potentially pathogenic bacteria Escherichia coli, Staphylococcus aureus, and Pseudomonas aeruginosa. Antimicrobial activity was assessed by the size (diameter in $\mathrm{mm}$ ) of the inhibition zones. Gentamicin sulphate at a concentration of $10 \mu \mathrm{g} / \mathrm{ml}$ was used as standard, while sterilized water was used as the negative control. Each inhibition experiment was repeated three times. Testing cultures were grown on beaf-extract agar for bacteria ("HiMedia", India). The Petri dishes with corresponding nutrient solutions were inoculated with daily testing culture suspension in physiological solution with a concentration of $1 \times 106$, dried, cut 5 $\mathrm{mm}$ diameter wells in agar, embedded with 3001 of extract and incubated at a temperature of $37^{\circ} \mathrm{C}$ for 2448 hours.

\section{Cytotoxicity Assay}

To evaluate the cytotoxic activity of the extracts there were used verified cultures of cancer cells carcinoma of the cervix (HeLa), larynx (HEp-2) obtained from the Bank of cell cultures of the Institute of Cytology RAS (Saint-Petersburg, Russia), and primary culture of healthy hepatocytes. The growth of cancer cells was determined according to a previously described protocol (Mossman, 1983) by the ability of viable cells to reduce yellow staining of 3-(4,5dimethyl-2-thiazolyl)-2,5-diphenyl-2H-

tetrazolium bromide (MTT) with the formation of blue formazan. For MTT assay cells were washed in phosphate buffer and collected by trypsinization, were placed in a 96 well cell plate, incubated, and treated with various concentrations of extracts -100 , 10 and $1 \mu \mathrm{g} / \mathrm{ml}$, stock solutions of the extracts were diluted with culture medium to the final concentration of DMSO of $0.1 \%$. After 72 hours incubation, the medium in each well was replaced by MTT solution $(5 \mathrm{mg} / \mathrm{ml}$ in phosphate buffer), cups were incubated for 4 hours under 5\% $\mathrm{CO} 2$ and $95 \%$ air at $37{ }^{\circ} \mathrm{C}$. Then MTT reagent was removed and the formazan crystals produced by viable cells were dissolved in DMSO and gently shaken. The absorption was determined at $492 \mathrm{~nm}$. Experiments were repeated three times. The percentage growth inhibition was calculated using following formula: \% cell inhibition = 100-[(At$\mathrm{Ab}) /(\mathrm{Ac}-\mathrm{Ab})] \mathrm{x} 100$, where At - absorption of the sample, $\mathrm{Ab}$ - absorption of the blank and Ac - absorption of the control. The effects of the extracts were expressed by IC50 values (the concentration of a substance that reduces the absorption of the treated cells by $50 \%$ with respect to 
untreated cells). "Cisplatin" (India) was used as the comparison drug, intact untreated cells was used as the control.

\section{$\alpha$-Amylase Inhibition Assay}

$100 \mu \mathrm{l}$ of the porcine pancreatic amylase (PPA) solution (1.1 U) in $0.1 \mathrm{M} \mathrm{Na}$ acetate buffer $\mathrm{pH} 7,2$ was added to $100 \mu \mathrm{l}$ of the extract and incubated at $30{ }^{\circ} \mathrm{C}$ for 10 minutes. The reaction was initiated by the addition of $100 \mu \mathrm{l}$ of $1 \%$ soluble starch solution and incubated at $37^{\circ} \mathrm{C}$. The reaction was arrested after $10 \mathrm{~min}$ of incubation by the addition of $5 \mathrm{ml}$ of iodine color reagent and absorbance was measured at $630 \mathrm{~nm}$. For the preparation of iodine reagent $0.5 \mathrm{~g}$ of crystalline iodine and $5 \mathrm{~g}$ of potassium iodide were dissolved in $250 \mathrm{ml}$ of water; for a working solution of $2 \mathrm{ml}$ of this reagent was adjusted to $100 \mathrm{ml}$ by $0.1 \mathrm{M} \mathrm{HCL}$. Acarbose was used as the standard PPA inhibitor, and solution of PPA without extract sample was used as negative controls. All the assays were carried out in triplicates and average percent inhibition of enzymes by the fungal extract was calculated using the following formula:(A0 - At)/A0x100\%, where A0 absorption of control sample, At is the absorption of test sample, respectively.

\section{Result and Discussion}

About 200 different Allium species were reported for the mountainous regions of Middle and South-West Asia (Hazalin et al., 2009). We have investigated endophytic fungi inhabited in endemic species $A$. filidens Regel and A. longicuspis Regel.

A.filidens Regel (piozi diona) refers to the section Allium of the subgenus Allium (Khassanov, 1996). Although A. filidens taxonomically quite distant from garlic, it is often used in the same way for medicinal purposes, in particular, the bulbs of this plant the locals used for headaches (Keusgen et al., 2006). A. longicuspis Regel, collected mainly in Central Asia, presumably is the ancestor of garlic (Khassanov, 1996).

As shown in table 1, 16 isolates of endophytic fungi in total were obtained from these plants. Of these, 7 isolates classified as Aspergillus, 3 isolates - as Penicillium, 3 isolates - as Alternaria , 2 isolates - as Fusarium, 1 isolate - as Cladosporium. The most number of isolates obtained from bulbs of $A$. filidens and leaves of $A$. longicuspis. The dominant endophytic fungi in A.filidens are Penicillium representatives, while in $A$. longicuspis various species of Aspergillus are dominated.

Three isolates obtained from bulbs and buds, belong to the rare species - Alternaria tenuissima, Cladosporium tenussimum and Aspergillus spectabilis, firstly observed in the conditions of Uzbekistan. There is information about Alternaria tenuissima isolated from the desert plant Tribulus terrestris L. producing enterotoxin with immune modulating and cytotoxic activity (Bashyal et al., 2014; Navruzshoev, 1994; Wu et al., 2014).

Recent studies indicate that many compounds produced by endophytes possess the antimicrobial activity. It is evident that the use of antimicrobial substances of endophytes is a promising way to overcome the increasing resistance of plants and human pathogens. Antimicrobial metabolites isolated from endophytes belong to diverse structural classes, including alkaloids, peptides, steroids, terpenoids, phenols, quinones, and flavonoids (Pimentel et al., 2011; Shentu et al., 2014; Yu et al., 2010).

Study of antibacterial activity of endophytes from Allium using the test cultures E. coli, 
S. aureus and $P$. aeruginosa, showed that 13 from 16 isolates of endophytes produce metabolites inhibiting the growth of pathogens in the range from 2 to $10 \mathrm{~mm}$ (Table 2). Moreover, 5 strains of endophytes exhibit antibiotic activity against two pathogens, the strains Alternaria sp. AL136L and A. versicolor - AL140R isolated from A. longicuspis, and Penicillium sp. - AF106 from A. filidens, are able to suppress the growth of three pathogens simultaneously. Although the antibacterial activity is observed mainly in the endophytes of A. longicuspis, the largest zone of inhibition observed for extract of Penicillium sp. - AF106 isolated from A. filidens (Fig. 1).

Thus the study of inhibiting properties of Allium associated endophytes against bacterial pathogens revealed their promising antibacterial potential.
Antidiabetic properties of endophytes were studied by in vitro inhibition of pancreatic $\alpha$-amylase as target enzyme. The results showed that endophytes isolated from $A$. filidens produce compounds with inhibitory activity. As can be seen from the presented data (Fig.2), in the range of concentrations 5-100 mg extracts of A. terreus - AF104S isolated from the stem, Penicillium sp. AF106 and Penicillium sp. - AF120 inhabiting plant bulbs, inhibited amylase activity very similar to inhibition by acarbose.

Determination of half-maximal inhibitory concentration of extracts also showed values close to IC50 of acarbose (Fig.3). Moreover, the data suggests that the strain A. terreus AF104S produces compounds with a lower IC50 compared with acarbose.

Table.1 Endophytic Fungi Isolated from Endemic Allium Species

\begin{tabular}{|c|c|c|}
\hline \multicolumn{3}{|c|}{ Allium filidens } \\
\hline 1 & Aspergillus terreus - AF104S & stem \\
\hline 2 & Penicillium sp. - AF105 & \multirow[t]{5}{*}{ bulb } \\
\hline 3 & Penicillium sp. - AF106 & \\
\hline 4 & Aspergillus terreus - AF107 & \\
\hline 5 & Penicillium sp. - AF120 & \\
\hline 6 & Cladosporium tenussimum - AF183 & \\
\hline 7 & Alternaria tenuissima - AF180 & bud \\
\hline \multicolumn{3}{|c|}{ Allium longicuspis } \\
\hline 8 & Fusarium sambucinum - AL135L & \multirow[t]{5}{*}{ leaf } \\
\hline 9 & Alternaria sp. - AL136L & \\
\hline 10 & Aspergillus terreus - AL138L & \\
\hline 11 & Aspergillus flavus - AL139L & \\
\hline 12 & Alternaria sp. - AL141L & \\
\hline 13 & Aspergillus ochraceus - AL137R & \multirow[t]{3}{*}{ root } \\
\hline 14 & Aspergillus versicolor - AL140R & \\
\hline 15 & Fusarium sp. - AL142R & \\
\hline 16 & Aspergillus spectabilis - AL184 & bulb \\
\hline
\end{tabular}


Table.2 Antibacterial Activity of Endophytes from Allium

\begin{tabular}{|c|c|c|c|c|}
\hline \multirow[t]{2}{*}{ \# } & Test cultures & E. coli & S.aureus & P.aeruginosa \\
\hline & Isolates & \multicolumn{3}{|c|}{ Pathogens' growth inhibition zone, $\mathrm{mm}$} \\
\hline \multicolumn{5}{|c|}{ Allium longicuspis } \\
\hline 1 & Fusarium sumbusinum - AL135L & 5,0 & - & - \\
\hline 2 & Alternaria sp. - AL136L & 5,0 & 5,0 & 5,0 \\
\hline 3 & Aspergillus terreus $-A L 138 L$ & - & 2,0 & 7,0 \\
\hline 4 & Aspergillus flavus - AL139L & - & - & 4,0 \\
\hline 5 & Alternaria sp. - AL141L & - & - & 6,0 \\
\hline 6 & Aspergillus ochraceus - AL137R & - & 3,0 & 7,0 \\
\hline 7 & Aspergillus versicolor - AL140R & 4,0 & 7,0 & 6,0 \\
\hline 8 & Fusarium sp. - AL142R & 2,0 & - & - \\
\hline 9 & Aspergillus spectabilis - AL184 & - & 3,0 & 5,0 \\
\hline \multicolumn{5}{|c|}{ Allium filidens } \\
\hline 10 & Aspergillus terreus - AF $104 S$ & - & 1,0 & 2,0 \\
\hline 11 & Penicillium sp. - AF106 & 10,0 & 7,0 & 7,0 \\
\hline 12 & Aspergillus terreus - AF107 & - & 2,0 & - \\
\hline 13 & Alternaria tenus - AF180 & - & 2,0 & 2,0 \\
\hline
\end{tabular}

Fig.1 Pathogens' Growth Inhibition Zone By Extracts of Penicillium sp. - af 106 isolated from bulb of $A$. filidens

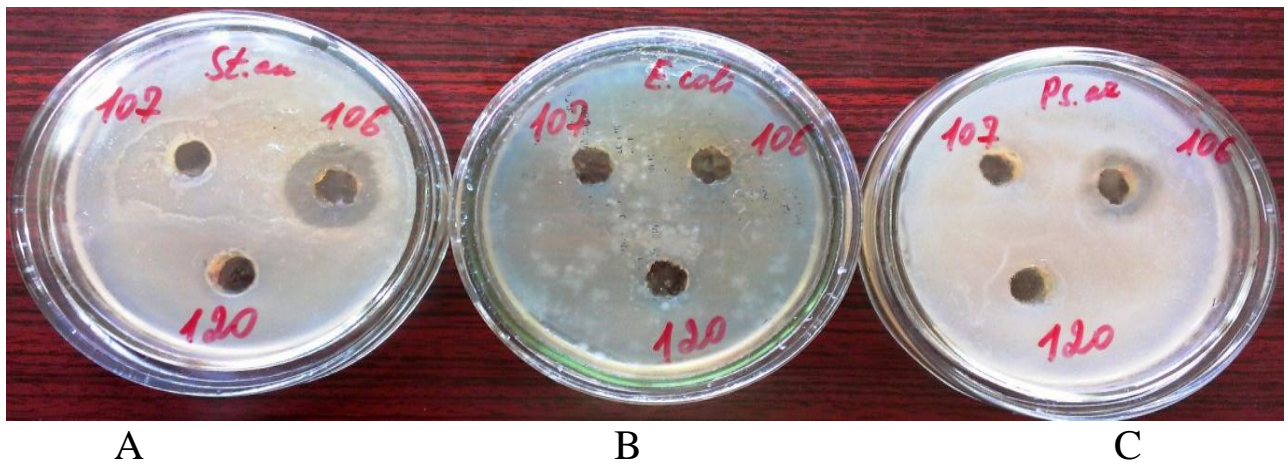

A - Staphylococcus aureus; B - Escherichia coli; C - Pseudomonas aeruginosa

Fig. $2 \alpha$-Amylase Inhibition by Extracts of endophytes from Allium filidens

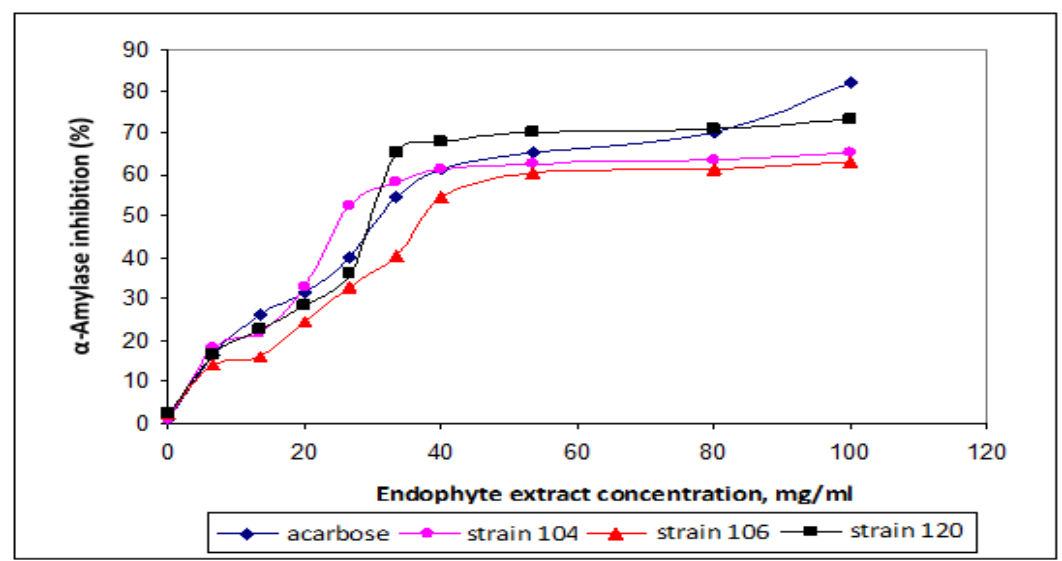


Table.3 Cytotoxic Activity of Endophytes from Allium filidens

\begin{tabular}{|c|c|c|c|c|c|c|c|c|c|}
\hline \multirow[t]{2}{*}{ Isolate } & \multicolumn{3}{|c|}{ Hepatocytes } & \multicolumn{3}{|c|}{ HeLa } & \multicolumn{3}{|c|}{ HEp-2 } \\
\hline & $\begin{array}{c}100 \\
\mu \mathrm{g} / \mathrm{ml}\end{array}$ & $\begin{array}{c}10 \\
\mu \mathrm{g} / \mathrm{ml}\end{array}$ & $1 \mu \mathrm{g} / \mathrm{ml}$ & $\begin{array}{c}100 \mu \mathrm{g} \\
/ \mathrm{ml}\end{array}$ & $\begin{array}{c}10 \\
\mu \mathrm{g} / \mathrm{ml}\end{array}$ & $\begin{array}{c}1 \\
\mu \mathrm{g} / \mathrm{ml}\end{array}$ & $\begin{array}{c}100 \mu \mathrm{g} \\
/ \mathrm{ml}\end{array}$ & $\begin{array}{c}10 \\
\mu \mathrm{g} / \mathrm{ml}\end{array}$ & $\begin{array}{c}1 \\
\mu \mathrm{g} / \mathrm{ml}\end{array}$ \\
\hline Aspergillusterreus -AF104S & $100 \pm 9,0$ & $98 \pm 5,5$ & $69 \pm 5,2$ & $8 \pm 0,05$ & $3 \pm 0,01$ & $0 \pm 0,01$ & $13,5 \pm 1,5$ & $11,5 \pm 0,5$ & $0 \pm 0,05$ \\
\hline Penicillium sp. - AF105 & $12 \pm 0,02$ & $0 \pm 0,05$ & $0 \pm 0,05$ & $66 \pm 5,9$ & $51 \pm 1,5$ & $25 \pm 1,5$ & $53 \pm 1,6$ & $16,5 \pm 0,7$ & $0 \pm 0,05$ \\
\hline Penicillium sp. - AF106 & $23 \pm 1,4$ & $4 \pm 0,01$ & $0 \pm 0,05$ & $31 \pm 0,9$ & $18,5 \pm 0,5$ & $7 \pm 0,5$ & $23 \pm 0,2$ & $18,5 \pm 0,5$ & $5,5 \pm 0,05$ \\
\hline Aspergillusterreus - AF107 & $62 \pm 5,6$ & $23 \pm 0,9$ & $19 \pm 0,5$ & $37 \pm 3,5$ & $13 \pm 0,5$ & $10 \pm 0,7$ & $35 \pm 1,5$ & $17 \pm 0,5$ & $12,5 \pm 0,5$ \\
\hline Penicillium sp. - AF120 & $100 \pm 9,8$ & $83 \pm 9,8$ & $24 \pm 0,7$ & $69 \pm 5,5$ & $33 \pm 1,3$ & $25 \pm 0,5$ & $64 \pm 5,6$ & $43,5 \pm 4,5$ & $22,5 \pm 2,1$ \\
\hline Cisplatin & $100 \pm 13,0$ & $66 \pm 11,2$ & $29 \pm 1,4$ & $95 \pm 11,4$ & $72 \pm 6,1$ & $25 \pm 7,2$ & $87 \pm 9,3$ & $49 \pm 6,5$ & $36 \pm 1,2$ \\
\hline
\end{tabular}

Fig.3 IC50 of Extracts of endophytes from Allium filidens

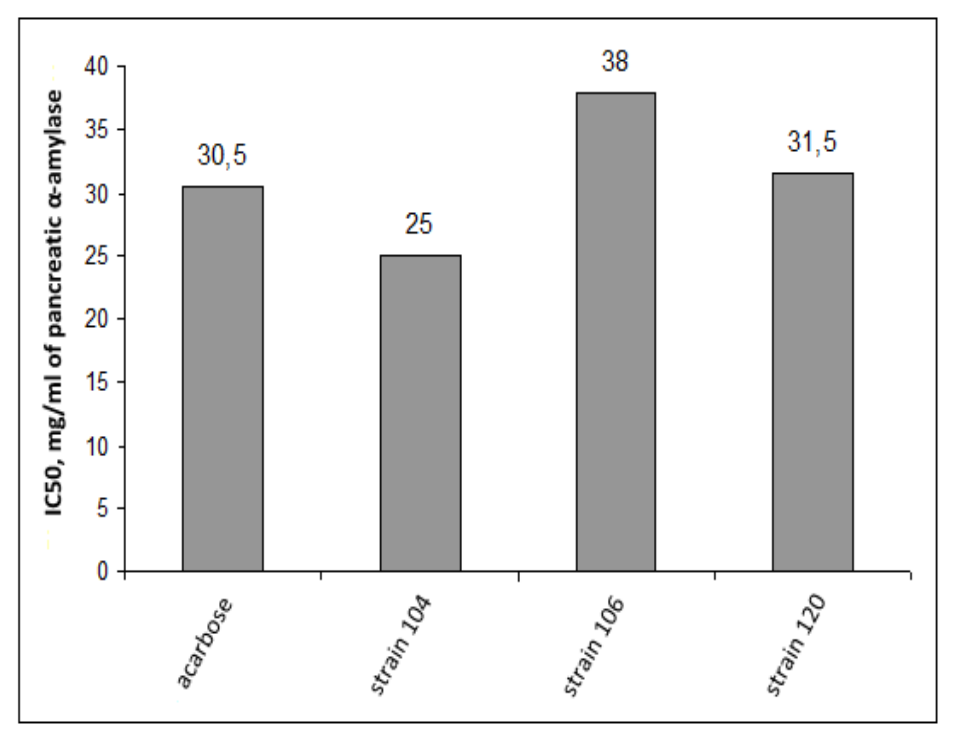


It should be noted that in the literature there are a number of reports of endophytic fungi with antidiabetic activity. Thus the extracts of the mycelium of 17 endophytic fungi isolated from the plant Salvadora oleoides were tested on animals with alloxan-induced diabetes. Significant reduction of blood glucose was caused by methanolic extracts of Aspergillus sp. JPY2 and Aspergillus sp. JPY1, and acetone extracts of Phoma sp. (Dhankhar et al., 2013). The ability to antidiabetic activity due to the presence of an inhibitor of $\alpha$-amylase was detected in Colletotrichum sp., isolated from Taxus sumatrana (Artanti et al., 2012). The isolation and identification of bioactive compounds revealed inhibitory activity of $\alpha$-amylase showed that this compound is unsaturated fatty acid (Santiago et al., 2014).

Obtained data on significant inhibitory activity of crude extracts of endophytes from A. filidens suggest further investigation of the nature of inhibitory compounds.

It is known that fungi are a rich source of chemotherapeutic metabolites (Sujkowska -Ziala et al., 2005). The study of metabolites of endophytic fungi opens up new opportunities to obtain new anticancer agents. Research in this direction is currently being developed intensively in different types of medicinal plants. So, a few endophytic fungi were selected from several plants that produce Taxol (Gangadevi and Muthumary, 2009; Kumaran et al., 2008). 23 endophytes with anti-cancer activity against 5 different cancer cell lines were isolated from Aquilaria sinensis (Jin-long et al., 2011). Endophytic fungus Phoma sp. isolated from Cinnamomum mollissimum was found to produce three well-known polyketides, one of which has a strong $(97,3 \%)$ and two moderate cytotoxic effect on the culture of leukemic cells P388 (Santiago et al., 2014).

It was observed that Penicillium sp. AF105 and Penicillium sp. - AF120 isolated from the bulbs of Allium filidens expose notable cytotoxic activity towards both cancer cell lines. The extracts of Penicillium sp. - AF105 on the line of HeLa cells exposed cytotoxicity close to cisplatin cytotoxicity at all three tested concentrations and no cytotoxicity against healthy hepatocytes, while extract of Penicillium sp. - AF120 affecting cytotoxic on HEp-2 cell line and hepatocytes as cisplatin. Thus obtained data indicated that endophytic fungi $A$. filidens produce secondary metabolites with cytotoxic properties.

It should be noted that the bioactivity of related endophytic fungi quite differed even though they are associated with the same species of the host plants. So, Alternaria sp. - AL136L isolated from the leaves of A. longicuspis exhibited antibacterial activity to $E$. coli, S. aureus, and $P$. aeurginosa, while Alternaria sp. AL141L - only to $P$. aeurginosa. Three strains of Penicillium sp. isolated from bulbs of $A$. filidens strongly differed in cytotoxic, antibacterial and anti-amylase activity.

The obtained data showed that endophytic fungi of wild Allium species produce compounds with antibacterial, antidiabetic and cytotoxic properties, apparently playing a certain physiological role in the metabolism of endophyte and plant in the process of symbiosis. However, the bioactive properties of the investigated Allium endophytes suggests their high biotechnological potential as sources of 
new secondary metabolites with therapeutic value.

\section{References}

Artanti, N., Tachibana, S., Kardono, L.B., Sukiman, H. 2012. Isolation of alpha-glucosidase inhibitors produced by an endophytic fungus Colletotrichum sp. TSC13 from Taxus sumatrana. Pak. J. Biol. Sci., 15(14): 673-9.

Augusti, K.T. 1996. Therapeutic values of onion (Allium cepa L.) and garlic (Allium sativum L.). Indian J. Exp. Biol., 34(7): 634-40.

Bashyal, B.P., Wellensiek, B.P., Ramakrishnan, R., Faeth, S.H., Ahmad, N., Gunatilaka, A.A. 2014. Altertoxins with potent anti-HIV activity from Alternaria tenuissima QUE1Se, a fungal endophyte of Quercus emoryi. J Asian Nat Prod Res., 16(7): 777-82.

Brewster, J.L. 2008. Onions and Other Vegetable Alliums. CABI Publishing: Wallingford, UK.

Dhankhar, S., Dhankhar, S., Yadav, J.P. 2013. Investigations towards new antidiabetic drugs from fungal endophytes associated with Salvadora oleoides. Decne. Med Chem., 9(4): 624-32.

Gangadevi, V., Muthumary, J. 2009. Taxol production by Pestalotiopsis terminaliae, an endophytic fungus of Terminalia arjuna (arjun tree). Biotechnol. Appl. Biochem., 529(1): 9-15.

Gutierrez, R.M.P., Gonzalez, A.M.N., Ramirez, A.M. 2012. Compounds Derived from Endophytes: A Review of Phytochemistry and Pharmacology. Curr. Med. Chem., 19: 2992-3030.
Hazalin, N.A., Ramasamy, K., Lim, S.M., Wahab, I.A., Cole, A.Lj, Majeed, A.A. 2009. Cytotoxic and antibacterial activities of endophytic fungi isolated from plants at the National Park, Pahang, Malaysia. BMC Complementary and Alternative Med., 9: 46.

Jin-long, C.U.I., Shun-xing, G.U.O., Peigen, X.I.A.O. 2011. Antitumor and antimicrobial activities of endophytic fungi from medicinal parts of Aquilaria sinensis. $J$. Zhejiang Univ-Sci B (Biomed \& Biotechnol), 12 (5): 385-392.

Keusgen, M., Fritsch, R.M., Hisoriev, H., Kurbonova, P.A., Khassanov, F.O. 2006. Wild Allium species (Alliaceae) used in folk medicine of Tajikistan and Uzbekistan. $J$. Ethnobiol. Ethnomed., 2: 18.

Khassanov, F.O. 1996. Conspectus of the wild growing Allium species of Middle Asia. In Plant life in Southwest and Central Asia. Izmir, EGE University Press, 141-159.

Kumaran, R.S., Muthumary, J., Hur, B.K. 2008. Production of taxol from Phyllosticta spinarum, an endophytic fungus of Cupressus sp. Engi. Life Sci., 8(4): 438-446.

Lang, G., Blunt, J.W., Cummings, N.J., Cole, A.Lj., Munro, M.H.G. 2005. Hirsutide a cyclic tetrapeptide from a spider-derived entomopathogenic fungus, Hirsutella sp. J. Nat. Prod., 68: 1303-1305.

Litvinov, M.A. 1967. Identification guide for microscopic fungi. Nauka, Leningrad.

Maaß, H.I., Klaas, M. 1995. Infraspecific differentiation of garlic (Allium sativum L.) by isozyme and RAPD markers. Theor. Appl. Genet., 91(1): 89-91. 
Mosmann, T. 1983. Rapid colorimetric assay for cellular growth and survival: application to proliferation and cytotoxicity assay. J. Immunol. Methods, USA, 65: 69.

Nair, D.N. and Padmavathy, S. 2014. Impact of Endophytic Microorganisms on Plants, Environment and Humans. Scientific World J., 1-11.

Navruzshoev, D. 1994. Nekotorye poleznye dikorastushchie rasteniya bassejna reki Bartang zapadnogo Pamira. Nauchno-tekhn. Byull. Vseross. Inst. Rasteniev., 233: 9295.

Padhi, L., Mohanta, Y.K., Panda, S.K. 2013. Endophytic fungi with great promises: A review. J. Adv. Pharm. Edu. Res., 3(3): 152-170.

Pimentel, M.R., Molina, G., Dionırsio, A.P., Marorstica, M.R., Pastore, G.M. 2011. The Use of Endophytes to Obtain Bioactive Compounds and Their Application in Biotransformation Process. Biotechnol. Res. Int., Article ID 576286, 11 pages.

Rabinowitch, H.D., Currah, L. 2002. Allium Crop Science: Recent Advances. CABI Publishing: Wallingford, UK.

Santiago, C., Lin Sun, Munro, M.H.G., Santhanam, J. 2014. Polyketide and benzopyran compounds of an endophytic fungus isolated from Cinnamonum mollissimum: biological activity and structure.
Asian Pac. J. Trop. Biomed., 4(8): 627-632.

Shentu, X., Zhan, X., Ma, Z., Yu, X., Zhang, C. 2014. Antifungal activity of metabolites of the endophytic fungus

Trichoderma brevicompactum from garlic Brazilian. J. Microbiol., 45(1): 248254.

Strobel, G.A., Daisy, B. 2003. Bioprospecting for microbial endophytes and their natural products. Microbiol. Mol. Biol. R., 67: 491-502.

Sujkowska-Ziala, K., Muszyska, B., Koska, G. 2005. Biologically active compounds of fungal origin displaying antitumor activity. Acta Poloniae Pharmaceutica and Drug Res., 62(2):153-159.

Wu, W.B.1, Yue, G.C., Huang, Q.L., Sun, L.L., Zhang, W. 2014. A new compound from an endophytic fungus Alternaria tenuissima. Bioorg. Med. Chem., 22(21): 61126116.

Xiao, Z., Storms, R., Tsang, A. 2006. A quantitative starch-iodine method for measuring $\alpha$-amylase and glucoamylase activities. Anal Biochem., 351(1): 146-148.

Yu, H., Zhang, L., Li, L., Zheng, C., Guo, L., Li, W., Sun, P., Qin, L. 2010. Recent developments and future prospects of antimicrobial metabolites produced by endophytes. Microbiol. Res., 165: 437-449.

\section{How to cite this article:}

Abdulmyanova, L.I., F.K. Fayzieva, D.M. Ruzieva, G.A. Rasulova, R.S. Sattarova and Gulyamova, T.G. 2016. Bioactivity of Fungal Endophytes associating with Allium Plants growing in Uzbekistan. Int.J.Curr.Microbiol.App.Sci. 5(9): 769-778. doi: http://dx.doi.org/10.20546/ijcmas.2016.509.088 